\title{
International energy R\&D spillovers and the economics of greenhouse gas atmospheric stabilization ${ }^{\hbar}$
}

\author{
Valentina Bosetti ${ }^{\mathrm{a}, \mathrm{b}}$, Carlo Carraro ${ }^{\mathrm{a}, \mathrm{b}, \mathrm{c}, \mathrm{d}, \mathrm{e}}$, \\ Emanuele Massetti ${ }^{\text {a,b,f, } *}$, Massimo Tavoni ${ }^{\text {a,b,f }}$ \\ ${ }^{a}$ Fondazione Eni Enrico Mattei, C.so Magenta, 63, 20123, Milan, Italy \\ b CMCC c/o Fondazione Eni Enrico Mattei Palazzo Querini Stampalia, Campo Santa Maria Formosa, Castello 5252, 30122, Venice, Italy \\ c University of Venice, Department of Economics, S. Giobbe, 873, 30121, Venice, Italy \\ d CEPR, United Kingdom \\ e CESifo, Germany \\ ${ }^{\mathrm{f}}$ Università Cattolica del Sacro Cuore, L.go A. Gemelli, 1, 20123, Milan, Italy
}

\section{A R T I C L E I N F O}

\section{Article history:}

Received 26 September 2007

Received in revised form 17 April 2008

Accepted 18 April 2008

Available online 2 May 2008

\section{JEL classifications:}

$\mathrm{HO}$

$\mathrm{H} 2$

H3

Keywords:

Climate policy

Energy R\&D

International R\&D spillovers

Stabilization

\section{A B S T R A C T}

It is now widely recognized that technological change will play a substantial role in reducing GHG emissions without compromising economic growth; hence, any better understanding of the process of technological innovation is likely to increase our knowledge of mitigation possibilities and costs. This paper explores how international knowledge flows affect the dynamics of the domestic R\&D sector and the main economic and environmental variables. The analysis is performed using WITCH, a dynamic regional model of the world economy, in which energy-related technological change is endogenous. The focus is on disembodied energy R\&D international spillovers. The knowledge pool from which regions draw foreign ideas differs between High Income and Low Income countries. Absorption capacity is also endogenous in the model. The basic questions are as follows. Do knowledge spillovers enhance energy-related technological innovation in different regions of the world? Does the speed of innovation increase? Or do free-riding incentives prevail and international spillovers crowd out domestic R\&D efforts? What is the role of domestic absorption capacity and of policies

\footnotetext{
is This paper is part of the research work being carried out by the Climate Change Modelling and Policy Research Programme of the Fondazione Eni Enrico Mattei and by the Climate Impacts and Policy Division of the EuroMediterranean Center on Climate Change. Financial support from the Italian Ministry of the Environment and the TOCSIN project is gratefully acknowledged. The authors are also grateful to participants at the Workshop on Macrodynamics, Technological Change and at CORE, Louvain 23-24 November 2006, at the Macroeconomics seminars, CAMA - Australian National University, at the 9th IAEE Conference, Florence, 11-13 June 2007, and at the 15th EAERE Annual Meeting, University of Macedonia, Thessaloniki, Greece, for helpful comments. The usual disclaimer applies.

* Corresponding author. Fondazione Eni Enrico Mattei, C.so Magenta, 63, 20123, Milan, Italy. Tel.: +39 0252036983 ; fax: +39 0252 036946.

E-mail address: emanuele.massetti@feem.it (E. Massetti).
} 
designed to enhance it? Do greenhouse gas stabilization costs drop in the presence of international technological spillovers? The new specification of the WITCH model presented in this paper enables us to answer these questions. Our analysis shows that international knowledge spillovers tend to increase free-riding incentives and decrease the investments in energy R\&D. The strongest cuts in energy R\&D investments are recorded among High Income countries, where international knowledge flows crowd out domestic R\&D efforts. The overall domestic pool of knowledge, and thus total net GHG stabilization costs, remain largely unaffected. International spillovers, however, are also an important policy channel. We therefore analyze the implication of a policy-mix in which climate policy is combined with a technology policy designed to enhance absorption capacity in Low Income countries. Significant positive impacts on the costs of stabilizing GHG concentrations are singled out. Finally, a sensitivity analysis shows that High Income countries are more responsive than Low Income countries to changes in the parameters. Additional empirical research efforts should thus be focused on the former. (c) 2008 Elsevier B.V. All rights reserved.

\section{Introduction}

It is now widely recognized that technological change will play a substantial role in reducing the cost of stabilizing GHG concentrations in the atmosphere. This is one of the reasons behind the many efforts recently devoted to the development of Integrated Economy-Climate Models, in which technological change is endogenous and responds to market and policy incentives. Significant improvements in the estimate of optimal abatement paths and costs have thus been achieved. In particular, by disentangling the determinants of knowledge accumulation, and linking them to incentives arising from emission targets, it is now possible to measure how climate policy-induced technological change reduces the costs of atmospheric stabilization (Grubb et al., 2006). However, despite this encouraging progress, the knowledge accumulation processes are still unclear, and the actual potential of technological innovation is far from being fully understood.

For example, only few studies on the economics of atmospheric stabilization have addressed the role of international knowledge flows in the process of knowledge production and accumulation. ${ }^{1}$ The transfer of knowledge across countries is instead crucial in shaping the diffusion of new technologies and in spreading basic scientific developments that gradually foster technological innovation in places different from where they were originally conceived. This is of central importance if we consider that new technologies are created and developed in a handful of countries, and that still greater concentration is recorded for the expenditure on energy R\&D. However, despite its concentrated origin, knowledge clearly flows across countries: developing economies import goods and services that embody the technological progress made in the laboratories of richer countries, and are increasingly exposed to the flow of knowledge that circulates among world research laboratories, the so-called disembodied knowledge flows. There is also a rich exchange of knowledge among industrialized countries, which often participate in joint research agreements to share the costs and risks of the most expensive projects. ${ }^{2}$ It is therefore crucial to understand how knowledge flows across countries in order to correctly assess by how much and at what cost technological change can increase energy efficiency and lower carbon intensity worldwide.

\footnotetext{
${ }^{1}$ In Buonanno et al. (2003) the world stock of knowledge affects productivity of the energy input and reduces the emission output ratio. Gerlagh and Kuik (2003) use a static general equilibrium model to analyze the effect of endogenous technical change and international technology diffusion on carbon leakage. Kemfert (2005) contains some attempts to account for international technology spillovers across countries via capital flows in a general equilibrium model. Some improvements are contained in Gerlagh (2006), again within a CGE framework. Clarke et al. (2008) review the recent literature on technological change in models of energy and the environment. They address some methodological issues related to knowledge spillovers but they do not discuss modelling assumptions and they mainly focus on inter-sectoral spillovers.

${ }^{2}$ A good example is ITER, a joint international research and development project that aims to demonstrate the scientific and technical feasibility of fusion power. The partners in the project are the European Union, Japan, the People's Republic of China, India, the Republic of Korea, the Russian Federation and the USA.
} 
The idea of reducing atmospheric stabilization costs by filling the knowledge gap between countries with more technological cooperation is very attractive indeed, and has been emphasized by several authors (e.g. Barrett, 1994, 2002; Carraro and Siniscalco, 1994; Grubb et al., 2002; Philibert, 2004; Buchner et al., 2005). On these grounds, any policy aimed at increasing the circulation of world knowledge should be promoted. For example, favourable treatment could be dispensed to knowledge flows, disclosure of sensitive information could be encouraged and joint development programs could be financed to increase knowledge sharing and the productivity of R\&D efforts. These proposals have also captivated the interest of policy makers: the basic idea of knowledge transfers is at the core of the recent Asia-Pacific agreement on climate change control.

However, the enhanced circulation of ideas and the free dissemination of technological innovation throughout the world do not necessarily imply that total global innovation will increase and abatement costs decrease. Several obstacles have been identified (Cf. Carraro, 2001 for a survey). For example, a given country may not have the capacity to absorb the flow of ideas and research results coming from other countries. Knowledge from international spillovers may crowd out domestic R\&D efforts. Free-riding incentives may induce some countries to reduce their own expenditures in Research and Development. The basic questions are therefore as follows. Do knowledge spillovers enhance energy technological innovation in different regions of the world? Do spillovers increase R\&D expenditures? Or do free-riding incentives prevail and international spillovers crowd out domestic R\&D efforts? What is the role of domestic absorption capacity and of policies designed to enhance it? And finally, do greenhouse gas stabilization costs drop in the presence of international technological spillovers? The new model specification presented in this paper enables us to answer these questions.

We address both researchers and policy makers by discussing modelling issues and analysing possible cost reductions achievable by greater knowledge diffusion. Our exploration of the role of international knowledge spillovers will be based on a new version of WITCH, a dynamic regional model of the world economy, in which energy-related technological change is endogenous and free-riding incentives from R\&D spillovers and other sources are also accounted for. Although embodied technology transfers play an important role in spreading technical know-how across the world, we focus our analysis on disembodied knowledge spillovers, i.e. on the positive externality that emerges from the exposure to foreign patents, scientists, laboratories and blueprints. ${ }^{3}$

In this paper, we disentangle three main issues that a modeller faces when dealing with international knowledge spillovers: first, we have to define the size and the characteristics of the international knowledge pool from which each country picks ideas to implement at home. Viewing the issue from another perspective, are knowledge stocks cumulated in different countries heterogeneous or homogeneous, and if they are a mix, to what degree do they overlap? Second, we must consider the process of knowledge absorption: are spillovers a "manna from heaven" that indiscriminately falls in each country, regardless of its degree of technological development, or is some domestic effort necessary to absorb foreign knowledge? Third, how do spillovers interact with the domestic knowledge production sector? Do patents, blueprints produced abroad, substitute those discovered at home?

Unfortunately, the limited empirical work on energy efficiency R\&D spillovers does not provide us with clear indications on the most appropriate model specification. ${ }^{4}$ We therefore make and compare some reasonable assumptions on absorption capacity, on the available international knowledge pool, and on the interactions between international spillovers and the domestic R\&D sector. These assumptions are then integrated into the equations of the WITCH model. This is then used to analyze how costs and benefits of GHG stabilization policy are affected by the presence of international R\&D spillovers, to define the impact of international spillovers on domestic R\&D efforts, and to determine what policy can be designed to enhance the dissemination of energy-saving technologies.

The rest of the paper is structured as follows: Section 2 briefly introduces the WITCH model and discusses our modelling of R\&D spillovers. Section 3 presents the calibration results, a new baseline, and analyzes the dynamics of stabilization investments in R\&D when international spillovers are explicitly modelled. In this section, we also present our new results on the costs and benefits of GHG stabilization policy. Section 4 discusses a policy-mix in which climate policy is combined with an R\&D incentive scheme designed to enhance the absorption capacity in developing countries, and thus the dissemination of new energy technologies. Section 5 shows the main outputs of our sensitivity analysis. A concluding section summarizes our results.

\footnotetext{
${ }^{3}$ For the role of trade in spreading technological knowledge see Keller (1997), Coe and Helpman (1995), Eaton and Kortum (1996, 1999).

${ }^{4}$ See Lanjouw and Mody (1996) for an analysis of innovation and international diffusion of environmental responsive technology.
} 


\section{The WITCH model}

\subsection{Short model description}

WITCH - World Induced Technical Change Hybrid - is a regional integrated assessment model structured to provide normative information on the optimal responses of world economies to climate damages. It is a hybrid model because it combines features of both top-down and bottom-up modelling: the top-down component consists of an inter-temporal optimal growth model in which the energy input of the aggregate production function has been integrated into a bottom-up like description of the energy sector. World countries are grouped in 12 regions that strategically interact when determining their optimal policies. A game theoretic framework is adopted to capture these strategic interactions. A climate module and a damage function provide the feedback on the economy of carbon dioxide emissions into the atmosphere.

WITCH's top-down framework guarantees a coherent, fully inter-temporal allocation of investments that have an impact on the level of mitigation - R\&D effort, investments in energy technologies, fossil fuel expenditures. The regional specification of the model and the presence of interdependencies among regions - through $\mathrm{CO}_{2}$, exhaustible natural resources, trade and technological spillovers - allow us to account for the incentives to free-ride. By solving an open-loop Nash game, the investment strategies are optimized taking into account both economic and environmental externalities.

WITCH contains a detailed representation of the energy sector, which allows the model to produce a reasonable characterization of future energy and technological scenarios and an assessment of their compatibility with the goal of stabilizing greenhouse gases concentrations. In addition, by endogenously modelling fuel (oil, coal, natural gas, uranium) prices, as well as the cost of storing the $\mathrm{CO}_{2}$ captured, the model can be used to evaluate the implication of mitigation policies on the energy system in all its components. In the next sub-sections, we focus on the representation of technical change; for a thorough description of the model, see Bosetti et al. (2006, 2007).

\subsection{Endogenous technical change (ETC) in the WITCH model}

Energy-related technological change is endogenous in WITCH. Thanks to the hybrid nature of the model, we portray endogenous technological change both in its bottom-up and top-down dimensions: R\&D investments designed to enhance energy efficiency increase the productivity of energy inputs in generating energy services; growing expertise driven by Learning-by-Doing (LbD) reduces the cost of power generation plants.

Following Popp (2004), in country $n$ at time $t$, technological advances are captured by a stock of knowledge, $\operatorname{HE}(n, t)$, combined with energy, $\operatorname{EN}(n, t)$, in a constant elasticity of substitution (CES) function that simulates the production of energy services, $\mathrm{ES}(n, t)$, demanded by the final good production sector:

$$
\mathrm{ES}(n, t)=\left[\alpha_{\mathrm{H}} \mathrm{HE}(n, t)^{\rho}+\alpha_{\mathrm{EN}} \mathrm{EN}(n, t)^{\rho}\right]^{1 / \rho} .
$$

The R\&D sector exhibits inter-temporal spillovers and the production of new "ideas" follows an innovation possibility frontier (Kennedy, 1964): knowledge is produced by "standing on the shoulders" of the nation's giants: investment in R\&D is combined with the stock of ideas already discovered and produces new knowledge which will be the base for new discoveries in the following years. A similar description of the R\&D sector can be found in the seminal paper by Romer (1990), in which the research sector productivity increases proportionally with the stock of knowledge cumulated in the past, giving rise to endogenous growth. Using data on patent citations, Jaffe et al. (1993), Trajtenberg et al. (1992) and Caballero and Jaffe (1993), have found evidence of state dependence at the industry level. ${ }^{5}$ In the specific narrower scope of our analysis, Popp (2002) finds that the energy R\&D sector exhibits diminishing returns. Denoting R\&D Investments with $I$, the production of new ideas in country $n$ at time $t, Z$, is modelled as follows:

$$
Z(n, t)=a I(n, t)^{b} \mathrm{HE}(n, t)^{c},
$$

\footnotetext{
${ }^{5}$ According to Rosenberg (1994), not only does technological progress in one nation show state dependence, but also path dependence. This interpretation of technological progress will be used in the next section to justify one of our modelling formulations.
} 
where $b+c<1$ so as to account for diminishing returns. Assuming that obsolescence makes a fraction $\delta$ of past ideas not fruitful for the purpose of current innovation activity, the law of motion of the R\&D stock is as follows:

$$
\operatorname{HE}(n, t+1)=\operatorname{HE}(n, t)(1-\delta)+Z(n, t) .
$$

Since in the present specification of the model we do not explicitly model non-energy R\&D, we assume an exogenous crowding out effect between energy and non-energy R\&D. ${ }^{6}$ We represent aggregated economies in which domestic externalities are fully internalized and the relevant return of investment is the social one, higher than the private one. The model is calibrated to address this discrepancy and returns to R\&D are set in line with the empirical literature to be four times higher than those for other investments, the externalities of which are instead assumed to be negligible. We do realize that our view on the knowledge failures of the domestic market is optimistic, but modelling non-cooperative knowledge markets in a computationally tractable way - also at the regional level - is a complex task that awaits further development of the model framework, Thus, the total cost of energy R\&D investments is as in Eq. (4):

$$
\operatorname{COST}_{\mathrm{R} \& \mathrm{D}}(t, n)=I(n, t)+4 \psi I(n t) .
$$

Where $\psi$ is the crowding out parameter which measures how many dollars of generic R\&D investment are lost per each dollar of energy R\&D investment. We set $\psi=0.5$ as in Popp (2004).

\subsection{International RED spillovers}

Researchers do not only "stand on the shoulders" of their predecessors but also on those of their neighbours. ${ }^{7}$ Knowledge flows across countries, either embodied in traded goods or disembodied in blueprints, patents, exchanges of ideas between researchers, and imitation. We concentrate here on disembodied knowledge spillovers. ${ }^{8}$ Since WITCH is a multiregional model, we can accommodate for the effect of disembodied knowledge spillovers by introducing a transmission channel across energy R\&D sectors in each region. Thus, the implications of these spillovers for investments in the creation of new ideas, climate policy costs and energy demand can all be analyzed.

Unfortunately, the empirical analysis of international spillovers induced by energy-saving R\&D investments is almost non-existent, and it is thus not possible to derive useful modelling insights. After comparing several alternative specifications of the equations representing technology spillovers in the model, here is the one that we propose as the most reliable. Countries/regions are exposed to a pool of world knowledge that can be considered as a global public good. A fraction of this knowledge is absorbed by each country and is available for use in the domestic R\&D sector. Different assumptions can be made on (1) the characteristics of world knowledge, on (2) the process of absorption and on (3) the way in which countries use this available information. We follow this three-step approach to highlight the most relevant issues and to illustrate our modelling choices.

\subsection{International knowledge pool}

We consider two distinct views of the pool of international knowledge. In the first, technological development is seen as a process in which all countries move upwards on the same knowledge ladder, with the least technologically advanced lying at the bottom and the technological innovator at the top; each region has a distinct position along the ladder at any time. Only knowledge still not possessed is attractive. Innovators receive scarce or no benefit from exposure to international knowledge while laggards harvest substantial gains. This was the view of technological progress put forward by Gerschenkron (1962) in his famous essay Economic

\footnotetext{
${ }^{6}$ For a study on R\&D crowding out in the short and medium term see Goolsbee (1998).

7 See Chapter 11 in Rosenberg (1982).

8 In a model with trade of heterogeneous intermediate and final goods it would be possible to give a more comprehensive description of knowledge flows. However, by modelling disembodied knowledge flows we concentrate on the circulation of frontier technological advancements that will be crucial for achieving high levels of energy efficiency. The importance of disembodied knowledge flows for energy efficiency improvements should not be underestimated also in the case of Low Income countries. Consider for example the knowledge necessary for the much needed improvements in electricity grids development and management in countries like China. Technical knowledge, processes and management software developed elsewhere will certainly improve efficiency and increase environmental benefits (see Guo et al, 2000; Streets, 2003; for electric grids in South Africa see Graebera et al., 2005). We thank David Zilberman for suggesting us examples of the importance of disembodied knowledge flows for Developing Countries.
} 
Backwardness in Historical Perspective: by adopting frontier technologies, backward countries could catch up with advanced economies at a relatively fast pace. More recently, the idea of knowledge that trickles down from the technological frontier to the technological laggards was explored by Acemoglu et al. (2006).

In our second description of world knowledge, we assume that countries move, at least partially, along independent technological patterns, and thus all external knowledge adds new insights to the domestic knowledge capital. Rosenberg (1994), in his second exploration of technological development, argues that indeed the technological development of countries tends to follow specific patterns influenced by the sequence of particular events which constitutes the history of the system. According to this view, the very same history of countries, their different regulatory regimes, and their economic and social environments, are drivers of technological differentiation. Indeed, for energy technologies we record a similar pattern of R\&D and technology discoveries, and a clear example of path-dependent technological progress is the success of the wind industry in Europe. When technologies tend to diverge, spillovers are a great source of benefit because they fill in important gaps that might otherwise remain unexplored.

According to the first view, the knowledge pool accessible to each region is represented by the technology that lies unexplored between the knowledge stock of any one country and the innovator's knowledge stock, whereas according to the second view, the knowledge pool is represented by the overall amount of world knowledge detained by other countries. Both these two representations of the pool of ideas available to each country capture some interesting and important features of the process of technology diffusion. In our analysis, we assume that the first view prevails in Low Income countries. Therefore, for Low Income countries, the absorption of knowledge from the innovator is the prevailing effect to model, the Gerschenkron effect. The second view, the situation described by Rosenberg with heterogeneous knowledge stocks, is to be preferred for High Income countries.

We combine these two different representations in one single formulation by assuming that the technological frontier is set not only by a single innovator but by the whole group of High Income countries, i.e. that the technological frontier is measured by the sum of the stocks of R\&D capital detained by these countries. High Income countries may draw from the knowledge stock of all other High Income countries, while the Low Income countries' knowledge pool consists of the knowledge accumulated in the more advanced economies (those setting the world's technological frontier). For Low Income countries, we describe the process of technological advancement as an upward movement along a technology ladder; the gap to fill is measured by the difference between each country's R\&D knowledge stock and the technological frontier capital. At high levels of technological development, however, countries specialize in different energy R\&D paths and thus they have the opportunity to benefit from all other High Income countries' R\&D stocks, which constitute the knowledge pool. By assuming a technological frontier determined by more than one country, we avoid the case of one single world leader, which cannot absorb any valuable knowledge from its followers, which is highly unrealistic when not dealing with a specific industry. If we define $\mathrm{HI}$ as the set of High Income Countries, Eq. (5) describes the knowledge pool for the $n$th country at time $t$ :

$$
\mathrm{KP}(n, t)=\sum_{n \in \mathrm{HI}} \operatorname{HE}(n, t)-\mathrm{HE}(n, t),
$$

where HE is the regional stock of knowledge as defined in Eq. (3). ${ }^{9}$

\subsection{Knowledge absorption}

Moving to the second logical step, we assume that only a fraction $\gamma(n, t)$ of the world's available pool of knowledge is absorbed by each country. The absorption parameter $\gamma$ might be an indicator of industrial policy or of the legal environment, or a measure of some effort to absorb international knowledge. We consider $\gamma$ as being primarily a function of domestic knowledge. In this we follow Cohen and Levinthal (1989), who were the first to suggest that the process of learning, far from being free, is costly and that most of this cost is borne by a stock of knowledge cumulated in the receiving country. Keller (2004) reinforces

\footnotetext{
9 The Knowledge Pool measures the widest possible inflow of knowledge and it is constructed assuming that knowledge is a perfect public good, free to flow from one country to another. However, by including absorption capacity in our formulation, we have incorporated an endogenous upper bound to knowledge appropriability which mimics exogenous constraints to knowledge circulation.
} 
this position in his survey of international knowledge spillovers by showing that an R\&D effort is needed to absorb international knowledge. By means of an empirical analysis of spillovers across OECD manufacturing industries, Kneller (2005) finds that absorptive capacity, rather than physical distance, plays an important role in determining the amount of knowledge transfers at the international level. Also Griffith et al. (2003) find that R\&D increases the absorption of knowledge spillovers and that neglecting this "second face" of knowledge investments necessarily leads to an underestimation of R\&D's social rate of return. Accordingly, we assume that the absorption capacity $\gamma(n, t)$ is a function of the distance of R\&D capital accumulated in the region with respect to the technological frontier. We use the ratio of one country's knowledge stock to the technological frontier as an indicator of this distance, as shown in Eq. (6):

$$
\gamma(n, t)=\frac{\mathrm{HE}(n, t)}{\sum_{n \in \mathrm{HI}} \mathrm{HE}(n, t)} .
$$

The further one country lies from the technological frontier, the lesser this country is able to absorb knowledge from the potentially available international knowledge pool. In other words, the lack of laboratories, scientific bodies, investments in $R \& D$ in Low Income countries is a serious obstacle to the profitable use of the knowledge that circulates in the world. The low absorptive capacity of Low Income countries realistically reduces the potentially very large inflow of knowledge from the technological frontier which determines the overall amount of knowledge spillovers. More in general, according to our modelling choice, also for High Income Countries absorption capacity is lower than one. Knowledge absorption is in fact determined by a wide variety of factors besides the level of technical expertise of the recipient. Exogenous factors such as patent policy, for example, can represent an important limitation to the appropriability of foreign knowledge (Cohen and Levinthal, 1989). ${ }^{10}$ Our modelling choices also, realistically, imply that High Income Countries may see their absorptive capacity decline over time if they do not innovate at the same pace of their advanced partners. This is indeed true for all technological breakthroughs that disrupt the paradigms in a discipline: even if close to the frontier, countries lagging behind might fail to reap any benefit from these new discoveries.

Accordingly, the spillover of international knowledge in region $n$ at time $t, \operatorname{SPILL}(n, t)$, is obtained by multiplying the Knowledge Pool and the absorption capacity:

$$
\operatorname{SPILL}(n, t)=\gamma(n, t) \cdot \mathrm{KP}(n, t)=\frac{\mathrm{HE}(n, t)}{\sum_{n \in \mathrm{HI}} \mathrm{HE}(j, t)}\left[\sum_{n \in \mathrm{HI}} \operatorname{HE}(n, t)-\mathrm{HE}(n, t)\right]
$$

Notice that this formulation implies that spillovers are a bell-shaped function of the country's R\&D knowledge stock. For Low Income countries, the peak of the curve lies halfway from the technological frontier. They start from very low absorption capacity levels and a very high knowledge pool, then progressively increase their knowledge stock and absorption capacity, but potential knowledge inflows diminish as they approach the technological frontier. ${ }^{11}$ Spillovers are thus first increasing and then decreasing along the transition from low to high technological progress levels. This mechanism guarantees relatively higher knowledge inflows to Low Income countries and increases the convergence among the two groups of countries. For High Income countries, spillovers increase until the knowledge stock of one country is equal to the sum of the knowledge stock of all the other High Income countries.

\footnotetext{
${ }^{10}$ At 2002, the base year, $\gamma$ is equal to 0.38 for USA, 0.31 for Europe (OLDEURO) and 0.26 for Japan (CAJANZ). The analytical framework closest to ours that has been tested empirically is in Cohen and Levinthal (1989). They assume that the absorption capacity $\gamma$, which is a positive function of R\&D investments, varies between 0 and 1 ; exogenous factors however limit the full absorption potential of a firm and thus multiply the absorption rate by a parameter $\theta$ for which they find a statistically significant value that ranges between 0.4 and 0.26 . Thus, assuming full knowledge-based absorption capacity, we obtain values for $\gamma$ which are in line with empirical estimates.

${ }^{11}$ As a term of comparison, in the stabilization exercise that we discuss in Section 3, the absorption rate is equal to 0.02 for China and 0.38 for the USA; the ratio of Chinese to USA Knowledge Pools is instead 1.6. At the beginning of the simulation timeframe, the ratio of international spillovers to the domestic R\&D knowledge stock is 0.98 for China and 0.62 for the USA. Spillovers are relatively higher for Low Income countries throughout the century: the same ratio in 2102 is 0.83 for China and 0.71 for the USA. Overall R\&D knowledge stocks partially converge over the century, with the ratio of Chinese to USA R\&D capital jumping from 0.05 to 0.56 . Also, the knowledge intensities of the two economies (Energy R\&D capital to GDP ratios) converge over the century, with their ratio declining from 2.7 to 1.5 . We thus allow steady, although incomplete, convergence in knowledge stocks across the century.
} 


\subsection{Spillover use}

The third and final step consists in defining how countries use the spillover in their process of knowledge generation. We assume that spillovers enter the domestic R\&D sector as an input in the innovation possibility frontier. Thanks to this highly standardized aggregation of different production inputs we can control for the elasticity of the production of new ideas to international R\&D spillovers, i.e. the coefficient $d$ in Eq. (8) below: ${ }^{12}$

$$
Z(n, t)=a(n) I_{R \& D}(n, t)^{b} \operatorname{HE}(n, t)^{c} \operatorname{SPILL}(n, t)^{d} .
$$

\subsection{Synthesis}

In the previous sub-sections, we described the logical steps that have been followed to introduce international energy R\&D spillovers in the WITCH model. There is a variety of other available options that were considered and explored. However, the one chosen is the strongest from a theoretical point of view, and it has the advantage of being tractable and easily understandable, while capturing the most interesting effects at work.

Notice that in our framework the public good features of the knowledge pool are somehow mitigated. Were knowledge a fully global public good, the incentive to free-riding would dominate, regions would invest less in technology R\&D and the overall production of knowledge would shrink. ${ }^{13}$ On the contrary, by giving knowledge a role in the process of knowledge absorption and by letting international R\&D spillovers augment the productivity of domestic investment, we have introduced forces that work against the freeriding incentive. This is in accordance with the literature on knowledge spillovers. As an example, Cohen and Levinthal (1989) have shown that when domestic R\&D increases absorption capacity and some general conditions hold, the incentive to invest more in $R \& D$ offsets the disincentive represented by free-riding, and world investments in R\&D eventually increase.

\section{Calibration, new baseline and the effects of spillovers on GHG stabilization}

Summing up, the new equation that describes the process of technology creation in country $n$ at time $t$ is as follows:

$$
Z(n, t)=a I_{R \& D}(n, t)^{b} \operatorname{HE}(n, t)^{c}\left\{\frac{\mathrm{HE}(n, t)}{\sum_{n \in \mathrm{HI}} \operatorname{HE}(n, t)}\left[\sum_{n \in \mathrm{HI}} \operatorname{HE}(n, t)-\mathrm{HE}(n, t)\right]\right\}^{d}
$$

We set the parameter $d$ to be equal to 0.15 , i.e. an increase of $1 \%$ of international spillovers increases the output of domestic ideas by $0.15 \%$. Since, to our knowledge, there is no empirical evidence that attributes the value of the elasticity of knowledge generation to international spillovers, we have chosen here a value slightly lower than the elasticity of knowledge production to domestic investments (equal to 0.18 ), and about one third of the elasticity with respect to past knowledge stock, which is equal to 0.53 in the model without spillovers (as in Popp, 2004). Thus, we give priority to domestic investments in generating new discoveries, and we assume that inter-temporal knowledge spillovers are stronger than the international ones. The effects and the robustness of this choice are tested through an appropriate sensitivity analysis (see Section 5).

We calibrated the new knowledge innovation frontier so as to reproduce the same time path of the R\&D knowledge stock that the model displays in the baseline without international spillovers, along the whole optimization period; ${ }^{14}$ this also yields exactly equal paths for output and for all energy variables and a very

\footnotetext{
12 For an analogous aggregation of spillovers to domestic investment and capital stock see Acemoglu (2002), p. 793.

13 The standard result that sees free-riding effects dominate has also been questioned by D'Aspremont and Jacquemin (1988), who show how, in a cooperative setting with strong knowledge flows, spillovers induce higher overall investment in R\&D due to the full internalization of positive externalities.

${ }^{14}$ We choose to act on R\&D stocks rather than on investments because we are primarily concerned with preserving energy intensities trends as in the baseline without spillovers. Energy intensities - determined by R\&D stocks with our modelling assumptions - were calibrated on historical trends and thus represent a good benchmark that we want to preserve, especially for their relevance in determining carbon emissions.
} 
Table 1

Reduction of R\&D investments when spillovers are modelled

\begin{tabular}{llllll}
\hline & $2022(\%)$ & $2042(\%)$ & $2062(\%)$ & $2082(\%)$ & $2102(\%)$ \\
\hline USA & -5.2 & -4.2 & -3.3 & -2.6 & -1.8 \\
OLDEURO & -3.8 & -3.2 & -2.6 & -2.1 & -1.4 \\
NEWEURO & -0.3 & -0.5 & -0.5 & -0.5 & -0.4 \\
KOSAU & -2.0 & -1.9 & -1.7 & -1.4 & -1.0 \\
CAJANZ & -3.3 & -2.8 & -2.2 & -1.8 & -1.2 \\
TE & -1.0 & -1.3 & -1.3 & -1.2 & -0.9 \\
MENA & -2.2 & -2.5 & -2.5 & -2.4 & -2.0 \\
SSA & 0.6 & -0.3 & -0.4 & -0.4 & -0.4 \\
SASIA & -1.2 & -1.7 & -1.8 & -1.7 & -1.3 \\
CHINA & -1.8 & -2.4 & -2.4 & -2.2 & -1.7 \\
EASIA & -1.4 & -1.9 & -2.0 & -1.9 & -1.5 \\
LACA & -2.0 & -2.2 & -2.1 & -1.9 & -1.4 \\
WORLD & -3.5 & -2.9 & -2.5 & -2.0 & -1.5 \\
HIGH INCOME & -4.1 & -3.4 & -2.7 & -2.1 & -1.5 \\
LOW INCOME & -1.7 & -2.1 & -2.1 & -2.0 & -1.6 \\
\hline
\end{tabular}

similar time evolution for R\&D investments. Calibration was performed by reducing $c$ in Eq. (9) so as to accommodate for the new input. By explicitly modelling international spillovers, we can separate the two "standing-on-shoulders" effects and attribute a correct nationality to the "giants" on which present researchers stand. Decreasing returns to scale are preserved. New values for parameter $c$ are country- and time-specific. ${ }^{15}$

We tested the above modelling choices by computing the costs and benefits of a 450 stabilization policy, i.e. a policy aimed at stabilizing atmospheric $\mathrm{CO}_{2}$ concentrations at $450 \mathrm{ppmv}$ ( $550 \mathrm{ppmv}$ when considering all gases) at the end of the 21st century. ${ }^{16}$ We computed the effects of this stabilization policy both with and without international energy R\&D spillovers. The two might in principle be very different, as the versions with and without spillovers have been calibrated to be the same only in the baseline scenario.

In the WITCH model, the group of High Income countries is composed by USA, OLDEURO, NEWEURO, KOSAU (Korea, South Africa and Australia), CAJANZ (Canada, Japan, New Zeland), while all other regions are labelled as Low Income. ${ }^{17} \mathrm{~A}$ world ceiling on emissions across the century is derived consistently from the stabilization target and emission allowances are distributed across world regions according to the Sovereignty rule, i.e. each year regions receive a fraction of permits equal to their share of world emissions in the base year 2002. This distribution scheme is, of course, highly questionable, but it provides a good testing ground to study policies to redistribute the effort of stabilization from Low Income to High Income countries. The latter may design policies to compensate Low Income countries for any distribution of permits that is considered inequitable, as will be shown in Section 4. A world carbon market equalizes marginal abatement costs worldwide. ${ }^{18}$

Table 1 shows a first important result: although our modelling choices rule out strong spillover effects, world investments in R\&D are always lower when spillovers are accounted for. The gap is about $3.5 \%$ in the first decades of the century and then progressively declines to $1.5 \%$ at the end of the century. Greater discrepancies are recorded if we look at more disaggregated data. High Income countries reduce investments the most, by cutting $4.1 \%$ of their R\&D effort at the beginning of the century. This figure then decreases gradually to $1.5 \%$ at

\footnotetext{
${ }^{15}$ The sum of the calibrated $c$ and $d$ is very close to the original value of 0.52 , which was used for $c$ alone. Variation over time is extremely limited: for the USA the recalibrated $c$ is equal to 0.401 in 2002 and to 0.391 in 2102; for CHINA the change is even less pronounced, from 0.386 to 0.387 over the century.

${ }^{16}$ The emission path consistent with the chosen stabilization target is obtained by running the cooperative solution of the WITCH model, in which all externalities are internalized, and is thus the efficient one.

${ }^{17}$ The aggregation of countries into twelve world regions is described in Bosetti et al. (2007) and can also be found at www.feemweb.it/witch.

${ }^{18}$ A distribution of emission allowances according to the "Equal per Capita" rule has also been tested. There are only very minor differences in R\&D investments and all the results illustrated in this section are confirmed. The reason is that the carbon price is independent of the distribution of permits, as expected from the theoretical prediction of the Coase theorem, and income effects have only mild impacts on investment choices.
} 
Table 2

Variation of share of high income countries investments

\begin{tabular}{lccccc}
\hline & $2022(\%)$ & $2042(\%)$ & $2062(\%)$ & $2082(\%)$ & $2102(\%)$ \\
\hline USA & -1.2 & -0.9 & -0.7 & -0.5 & -0.3 \\
OLDEURO & 0.3 & 0.2 & 0.1 & 0.1 & 0.0 \\
NEWEURO & 4.0 & 3.0 & 2.2 & 1.6 & 1.1 \\
KOSAU & 2.2 & 1.5 & 0.7 & 0.4 \\
CAJANZ & 0.8 & 0.6 & 0.4 & 0.3 & 0.2 \\
\hline
\end{tabular}

the end of the simulation period. For Low Income countries we record only a mild $1.7 \%$ reduction in the first decades, then a slightly greater gap at the middle of the century when they cut their efforts by $2.1 \%$, and finally a decline to a $1.6 \%$ reduction at the end of the century. The difference in behaviour between High and Low Income countries during the first decades of the century is explained by the fact that, for Low Income countries, spillovers increase at a faster rate as they augment their knowledge stocks and move along the bell-shaped curve that governs knowledge inflows, as explained in the previous section.

It is also worth noting that among High Income countries the greatest reductions are recorded in USA, OLDEURO and CAJANZ, with the greatest difference found in USA, the smallest in CAJANZ, and OLDEURO in the middle. Investments decrease less in KOSAU and NEWEUROPE, the other two High Income countries, than in the top three countries/regions and in both, the share of investments at the frontier, i.e. the share of all High Income countries' investments, increases by $4 \%$ and $2.2 \%$, respectively, in the first decades of the century. Thus, our results show that spillovers enhance convergence among countries at the frontier, as detailed in Table 2.

Among Low Income countries, we record reductions in investments for all countries except for SSA (Sub-Saharan Africa) that slightly increases its investments when spillovers are introduced. However, as shown in Table 3, during the first decades of the century, reductions are inferior to those recorded for High Income countries and thus their share of world R\&D between 2002 and 2032 increases, ranging from 4.3\% for SSA to $1.3 \%$ for MENA (Middle East and North Africa). As a group, Low Income countries increase their share of world investments between 2002 and 2082 and slightly invert the trend at the end of the century.

Summing up, our results show some convergence in R\&D investment shares among High Income countries. As a group, these countries lose ground in favour of Low Income countries in the first decades of the century. Hence, our formulation of international R\&D Spillovers captures the convergence process from multiple perspectives. It must also be stressed that these results are obtained within a stabilization scenario in which, even without spillovers, there is a high degree of convergence in R\&D investments and knowledge stocks across world regions. International spillovers thus reinforce an already strong underlying convergence process. ${ }^{19}$

Changes in the stock of R\&D are instead negligible, as shown in Table 3. International knowledge inflows substitute domestic investments and the cuts are spread across the economy. In addition, energy R\&D expenditures at the end of the century, when they are at their highest level, range from $0.12 \%$ to $0.02 \%$ of GDP, respectively, for USA and SSA. Therefore, the change induced by spillovers is small in absolute terms. As a consequence, gains in terms of stabilization costs are also negligible. As an example, over the whole century, the USA save 72 USD Billions over a cumulated GDP of more than 2100 Trillions in our stabilization scenario, i.e. a modest $0.003 \%$.

Given that the stock of domestic R\&D changes only slightly, and that we do not record any significant effect of spillovers on the available income, there is also no adjustment in the investment in all energy technologies, and the price of emissions permits does not vary when spillovers are introduced. This also explains the virtually unchanged distribution of emissions for all countries.

This result has been tested with different formulations, and follows from the fact that spillovers induce limited $R \& D$ investment reductions. It should be stressed that the specification of $R \& D$ that is subject to

\footnotetext{
${ }^{19}$ In order to control for differences between the two stabilization scenarios that might arise from small discrepancies between the baselines with and without spillovers, we have also compared the changes in investments in R\&D induced by the stabilization policy with and without spillovers and we are able to confirm the results illustrated in the text.
} 
Table 3

Variation of share of world investments in energy R\&D

\begin{tabular}{lrrrrr}
\hline & 2022 & 2042 & 2062 & 2082 & 2102 \\
\hline USA & $-1.8 \%$ & $-1.3 \%$ & $-0.9 \%$ & $-0.6 \%$ & $-0.3 \%$ \\
OLDEURO & $-0.3 \%$ & $-0.3 \%$ & $-0.1 \%$ & $0.0 \%$ & $0.1 \%$ \\
NEWEURO & $3.4 \%$ & $2.6 \%$ & $2.0 \%$ & $1.6 \%$ & $0.6 \%$ \\
KOSAU & $1.6 \%$ & $1.1 \%$ & $0.8 \%$ & $0.3 \%$ & $0.5 \%$ \\
CAJANZ & $0.2 \%$ & $0.2 \%$ & $0.2 \%$ & $0.8 \%$ & $0.3 \%$ \\
TE & $2.6 \%$ & $1.7 \%$ & $1.1 \%$ & $-0.3 \%$ & $0.6 \%$ \\
MENA & $1.3 \%$ & $0.4 \%$ & $-0.1 \%$ & $1.7 \%$ & $-0.5 \%$ \\
SSA & $4.3 \%$ & $2.8 \%$ & $2.1 \%$ & $0.3 \%$ & $1.2 \%$ \\
SASIA & $2.4 \%$ & $1.3 \%$ & $0.6 \%$ & $-0.1 \%$ & $0.2 \%$ \\
CHINA & $1.7 \%$ & $0.6 \%$ & $0.1 \%$ & $0.1 \%$ & $-0.2 \%$ \\
EASIA & $2.2 \%$ & $1.1 \%$ & $0.4 \%$ & $0.2 \%$ & $0.0 \%$ \\
LACA & $1.6 \%$ & $0.8 \%$ & $-0.1 \%$ & $0.1 \%$ \\
HI & $-0.6 \%$ & $-0.4 \%$ & $-0.2 \%$ & $0.1 \%$ & $0.0 \%$ \\
LI & $1.9 \%$ & $0.9 \%$ & $0.3 \%$ & $-0.1 \%$ \\
\hline
\end{tabular}

spillovers pertains only to the energy efficiency improvements of the economy. Stringent climate targets will likely call for additional R\&D activities aimed at developing new carbon free technologies ("backstops").

\section{GHG stabilization and technology diffusion: a policy exercise}

Even though spillovers are shown to have a marginal impact on the amount and distribution of R\&D investments, and only a minor one on energy investments and overall stabilization costs, they may nonetheless play an important role in shaping investment and emission strategies. Assume indeed that a set of countries decide to adopt an energy R\&D policy to stimulate the development of a new low-carbon energy technology. The overall effects of this policy can be properly assessed only in a model with international spillovers, where the benefits of R\&D investments are not limited to the country where investments are made. As another example, consider a policy aimed at increasing the circulation of world knowledge, indistinctly among regions or with a special focus on some areas. This kind of policy intervention is frequently debated (Cf. Barrett, 2001) and could be the core of a future GHG stabilization treaty (this is recommended, for example, in the June 2007 Heiligendamm Summit Declaration). Again, the overall effects of such policy can only be studied in models in which knowledge flows are explicitly modelled.

Let us analyze, in this paper, a third case, in which a $450 \mathrm{ppm}$ stabilization policy, based on the introduction of a global permit market, is coupled to a policy to foster knowledge dissemination. Let us assume that emission permits are distributed according to the Sovereignty rule as in the previous stabilization exercise. With such a distribution of emission permits - rather extreme but often debated in the policy arena - complementary policies to alleviate the burden falling on Low Income countries would be needed to redistribute the cost of stabilizing GHG concentrations. R\&D cooperation policies are certainly among the most promising tools to attain this objective.

We consider here an R\&D cooperation policy in which High Income countries use a fraction of the revenues from emission permit sales to build absorption capacity in Low Income countries. This is shown in Eq. (10), which modifies Eq. (9):

$$
Z(n, t)=a I_{\mathrm{R} \& \mathrm{D}}(n, t)^{b} \mathrm{HE}(n, t)^{c}\left\{\left[\frac{\operatorname{HE}(n, t)+\operatorname{ABS}(n, t)}{\sum_{n \in \mathrm{HI}} \operatorname{HE}(n, t)}\right]\left[\sum_{n \in \mathrm{HI}} \operatorname{HE}(n, t)-\mathrm{HE}(n, t)\right]\right\}^{d} \forall n \in \mathrm{LI}
$$

where $\operatorname{ABS}(n, t)$ is the Low Income countries absorption capacity stock, which derives from the flow of R\&D cooperation aid, $\operatorname{AID}(t)$, financed using a fraction of the revenues from carbon trading of High Income countries, CT $(n, t)$, and equally shared among the seven Low Income regions. $\mathrm{ABS}(n, t)$ evolves accordingly as shown in Eq. (11):

$$
\begin{aligned}
& \operatorname{ABS}(n, t+1)=\operatorname{ABS}(n, t)(1-\delta)+\frac{\operatorname{AID}(t)}{7} \quad \text { for } n \in \mathrm{LI} \\
& \operatorname{AID}(t)=\left[\pi(t) \sum_{n \in \mathrm{HI}} \mathrm{CT}(n, t)\right]
\end{aligned}
$$

The fraction $\pi(t)$ of revenues from carbon trading devoted to fund R\&D technology transfers and cooperation declines across time as shown in Table 4. The world fund devoted to increasing absorption capacity in Low Income countries ranges between 2 and 105 billion USD. 
Table 4

Financial aid for R\&D absorption capacity

\begin{tabular}{lcccccc}
\hline & 2007 & 2022 & 2042 & 2062 & 2082 & 2102 \\
\hline$\pi$ & $78 \%$ & $37 \%$ & $14 \%$ & $5 \%$ & $2 \%$ & $1 \%$ \\
AID (Billions, 1885 USD) & 2 & 35 & 87 & 105 & 70 & 37 \\
\hline
\end{tabular}

Table 5

Change of stabilization costs

\begin{tabular}{lcr}
\hline & $450+$ R\&D absorption (\%) & $450+$ transfer (\%) \\
\hline USA & 13.06 & 12.00 \\
OLDEURO & 210.76 & 193.66 \\
NEWEURO & 0.39 & 0.83 \\
KOSAU & 1.99 & 2.38 \\
CAJANZ & 10.28 & 9.55 \\
TE & -2.04 & -2.43 \\
MENA & -2.72 & -1.21 \\
SSA & -1.90 & -5.10 \\
SASIA & -2.34 & -1.43 \\
CHINA & -2.02 & -1.11 \\
EASIA & -2.24 & -1.21 \\
LACA & -2.46 & -1.47 \\
WORLD & -0.67 & -0.09 \\
HIGH INCOME & 11.33 & 10.63 \\
LOW INCOME & -2.30 & -1.55 \\
\hline
\end{tabular}

We find that an R\&D cooperation policy targeted to enhance absorption capacity reduces stabilization costs in Low Income countries by $2.3 \%$, with respect to the standard stabilization policy examined in Section 3. High Income countries suffer the loss of a fraction of carbon trading revenues and see stabilization costs increasing, as a group, by $11.3 \%$ (but their quota of world stabilization costs remains fairly low because of the application of the sovereignty principle in allocating permits). Overall, as detailed in Table 5, we record a reduction of world GHG stabilization costs. ${ }^{20}$

Low Income countries benefit from enhanced absorption capacity and build larger and less expensive stocks of Energy R\&D, which increase energy efficiency and reduce dependency on carbon trading to meet stabilization targets. The carbon market reacts to a lower demand of emission permits by lowering the price of carbon (Fig. 1), which ultimately reinforces the benefits of higher energy efficiency.

It is interesting to see that the increase of foreign knowledge spillovers associated with a higher absorption capacity creates, in itself, a greater flow of new ideas, but it also increases the productivity of domestic R\&D and thus stimulates larger investments in knowledge, as shown in Table 6 . R\&D investments in High Income countries decrease, but not enough to offset the increment of R\&D investments in Low Income countries, and the world as a whole is now set on a new path with overall higher Energy R\&D expenditures.

It is reasonable to wonder if the same gains could be achieved with a simpler, non-targeted, lump-sum transfer of the same amount of resources from High Income to Low Income countries. We tested this alternative policy by adding to the budget constraint of Low Income countires the same amount of resources that were used to increase absorption capacity (AID) and we found that this would be a less efficient way for transferring income to Low Income countries. Table 5 shows that global stabilization costs would still be lower when a redistribution policy is implemented, but gains are greater when the same amount of resources is targeted to increase absorption capacity. ${ }^{21}$ The additional resources are spread across a variety of investment opportunities (not least, consumption itself) instead of being channelled to

\footnotetext{
20 The change is very high for OLDEURO because its initially very low level of stabilization costs magnifies, in percentage terms, the income transfer.

21 Sub-Saharan Africa is a notable exception; this may suggest that for very poor countries income support policies can be more valuable than interventions on R\&D sectors which are still too underdeveloped.
} 


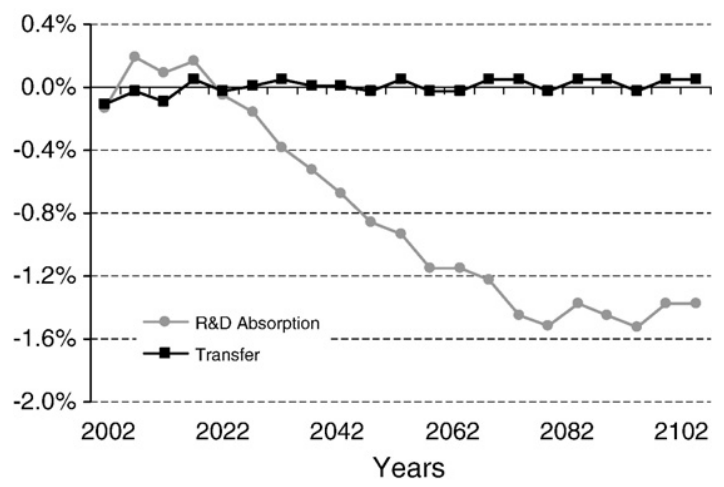

Fig. 1. Change of carbon price induced by the R\&D absorption policy and the transfer policy.

achieve higher energy efficiency. As a result, the non-targeted cooperation policy does not induce a lower worldwide path of abatement costs, as shown by the largely unchanged pattern of carbon price in Fig. 1. Why would this happen if countries are still free to allocate all their resources to greater R\&D investment? At least in part, this would happen because under the untargeted transfer policy each single country would be a price taker and would act in an uncoordinated fashion in the carbon market: it would not perceive the benefit of increasing energy efficiency in terms of lower carbon prices and, were it to perceive it, strategic consideration would anyway prevent it from acting in an uncoordinated manner.

The set of strategic interactions in the carbon market does not change with a policy that increases absorption capacity, but in this case resources would be channelled towards energy efficiency improvements and the whole policy would act as a coordination mechanism.

Thanks to the multi-faceted non-cooperative structure of our model it would be possible to examine a wide variety of other R\&D policies in a stabilization context and the one presented above was meant to provide just a taste of other possible exercises. Interesting insights could be derived by studying, for example, (1) knowledge cooperation policies among High Income countries, (2) lower exogenous constraints to knowledge appropriability, (3) cooperation regimes between signatory and non-signatory countries. Despite these very interesting developments, the focus of this paper wants to be on methodological issues and we will leave the analysis of further policy scenarios to future exercises.

\section{Sensitivity analysis}

As previously discussed, there is some uncertainty over the value to be assigned to the elasticity of knowledge creation in international R\&D spillovers. We therefore tested the robustness of our findings by attributing different values to this elasticity. Given the shortage of empirical estimates for this parameter, we used the values of similar variables included in the model - especially the value of elasticity of knowledge creation in domestic investments - and performed sensitivity analyses relative to this benchmark.

Specifically, we used a symmetric interval around the central value of 0.15 by setting 0.20 and 0.10 as upper and lower bounds, respectively. With the upper bound value, the elasticity of knowledge creation to international spillovers is greater than 0.18 , which is the value of domestic investments. 0.20 is thus a considerably high level for parameter $d$. With the lower bound, instead, we allow for a sufficiently low relevance of international R\&D spillovers by assuming that a $1 \%$ increase of foreign knowledge is almost half as powerful as a $1 \%$ increase in domestic investment in creating new ideas. ${ }^{22}$

Sensitivity analysis shows that for all values of the parameter $d$ considered, investments in energy R\&D in a 450 ppmv stabilization scenario decline in almost all countries when spillovers are explicitly modelled (the only exception is SSA). This adds robustness to the results described in the previous section.

\footnotetext{
${ }^{22}$ For each value of the parameter $d$ that we test in the sensitivity analysis a new baseline has been recalibrated by varying the coefficient $c$ which governs intertemporal spillovers inside each region.
} 
Table 6

Change of $R \& D$ capital and $R \& D$ investments when absorption capacity building policy is implemented

\begin{tabular}{llllll}
\hline & \multicolumn{2}{l}{ R\&D capital at 2102} & & \multicolumn{2}{l}{ R\&D investments (cumulative, 2002-2102) } \\
\cline { 2 - 3 } \cline { 5 - 6 } & $450+$ R\&D absorption (\%) & $450+$ transfer (\%) & & $450+$ R\&D absorption (\%) & $450+$ transfer (\%) \\
\hline USA & 0 & 0 & -1 & 0 \\
OLDEURO & 0 & 0 & -1 & 0 \\
NEWEURO & 0 & 0 & -1 & 0 \\
KOSAU & 0 & 0 & -1 & 0 \\
CAJANZ & 0 & 0 & -1 & 0 \\
TE & 56 & 0 & 6 & 0 \\
MENA & 46 & 0 & 3 & 0 \\
SSA & 93 & 0 & 13 & 0 \\
SASIA & 53 & 0 & 4 & 0 \\
CHINA & 46 & 0 & 3 & 0 \\
EASIA & 53 & 0 & 4 & 0 \\
LACA & 47 & 0 & 3 & 0 \\
WORLD & 25 & 0 & -1 & 0 \\
HIGH INCOME & 0 & 0 & 4 & 0 \\
LOW INCOME & 52 & & & 0 \\
\hline
\end{tabular}

Figs. 2-5 show, for different years, the relationship found between parameter $d$ and the magnitude of cuts in energy R\&D investments, with respect to the stabilization scenario without spillovers. The strongest responses are recorded from High Income countries, but the sensitivity of Low Income countries progresses over time, reaches its maximum before the end of the century, and then regresses to converge towards values similar to those found for High Income countries. For these countries we find instead a constantly declining responsiveness to spillovers across time.

This implies that our model yields different reactions to spillovers as a function of the degree of economic development (the level of knowledge accumulation). Because of their low absorption capacity, Low Income countries are initially prevented from reaping the full benefits of the available international pool of technologies. However, as their knowledge stock increases, and as the productivity of domestic investments is gradually enhanced by foreign investments, Low Income countries become more reactive to foreign knowledge flows.

Let us now consider the responsiveness of domestic investments to international spillovers in the first half of the century. In case of "standing-on-shoulders" effects, as in WITCH, investments in the next decades will be crucial to determine future knowledge stocks and energy intensities in the subsequent decades. It is thus important to understand the effect of knowledge spillovers on these early investments. We have seen that while Low Income countries investments' decisions are relatively rigid with respect to the degree of international spillovers, High Income countries show a higher margin of variation, that ranges from $-2.8 \%$ to $-6 \%$ in 2012 . This result bears some meaningful implications: empirical research should above all be

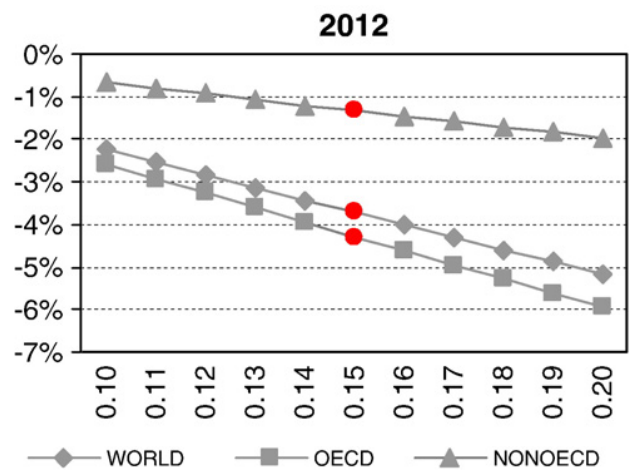

Fig. 2. Change of R\&D investments in 2012, wrt to the Baseline Scenario, for different values assigned to parameter $d$. 


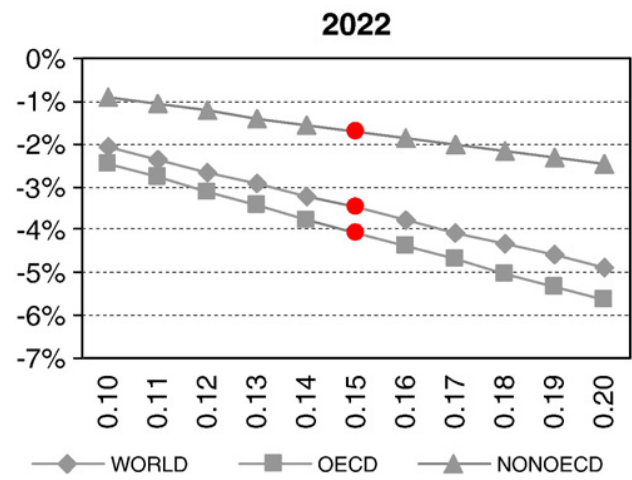

Fig. 3. Change of R\&D investments in 2022, wrt to the Baseline Scenario, for different values assigned to parameter $d$.

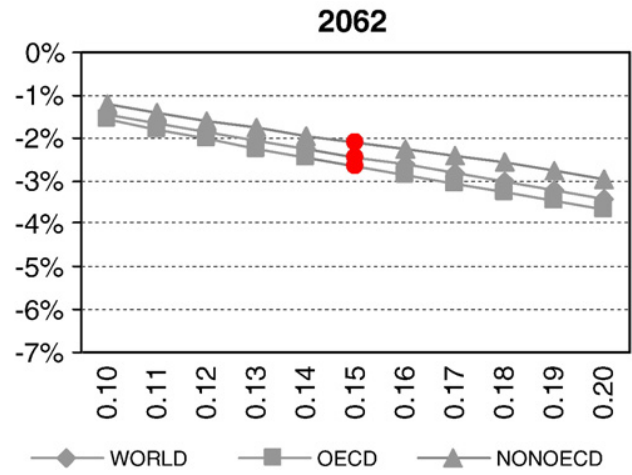

Fig. 4. Change of R\&D investments in 2062, wrt to the Baseline Scenario, for different values assigned to parameter $d$.

addressed to estimate the impact of energy R\&D spillovers on High Income countries, and the lack of reliable data on Low Income countries should not prevent us from performing model simulations.

The shadowed areas in Figs. 6 and 7 show the range of reductions in R\&D investments for USA and CHINA, with respect to the stabilization scenario without spillovers. The area included between the two extreme parameter values of 0.10 and 0.20 has been shadowed to highlight the range of values found; the dotted lines correspond to intermediate values assigned to the parameter $d$ and the solid line corresponds to the central value 0.15 . As noted above, the widest range is recorded for the country with the highest level

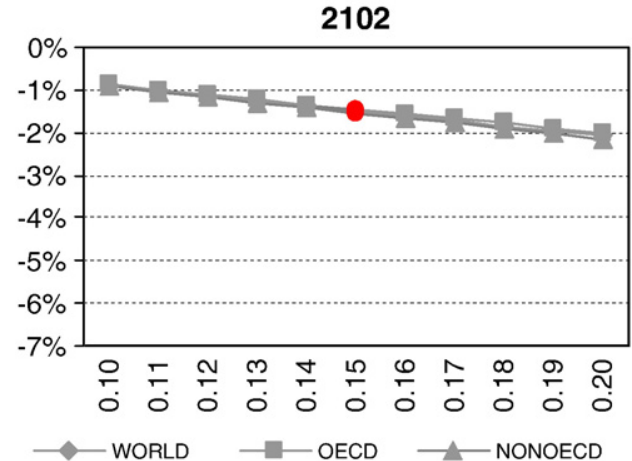

Fig. 5. Change of R\&D investments in 2102, wrt to the Baseline Scenario, for different values assigned to parameter $d$. 


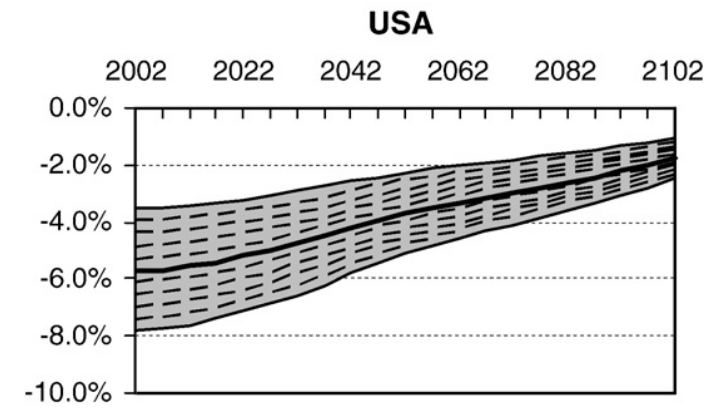

Fig. 6. Change of R\&D investments in USA, wrt to the Baseline Scenario, for the range of values assigned to parameter $d$.

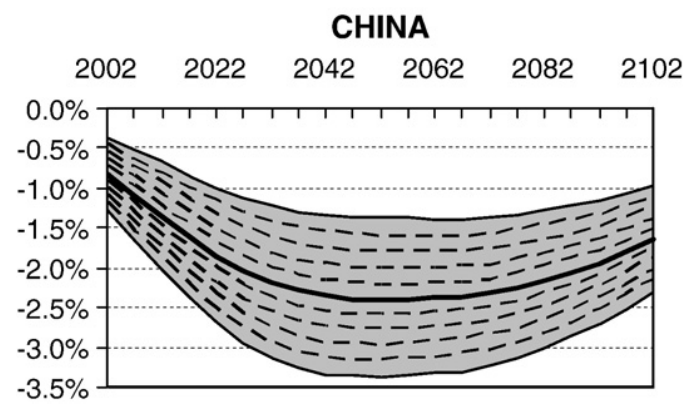

Fig. 7. Change of R\&D investments in CHINA, wrt to the Baseline Scenario, for the range of values assigned to parameter $d$.

of capital per capita. ${ }^{23}$ CHINA starts from low ranges, but as income per capita and knowledge increase, and spillovers become more important, the range increases as well. This is due to the bell-shaped curve that governs spillovers, as explained in Section 2.

\section{Conclusions}

In order to achieve the emission reductions needed for stabilizing GHG concentrations in the atmosphere at safe levels, new technologies must be developed to soften the link between economic/ demographic growth and carbon emissions. The development of technologies that allow for a more efficient use of energy is part of this effort and it will certainly play a substantial role in any future stabilization policy. New technologies like hybrid vehicles, for example, allow for a substantial reduction of energy consumption, while delivering the same services. More efficient air conditioning systems would significantly cut energy consumption, while preserving comfort conditions.

The discovery of new technologies and the development of new ideas is, at least partially, a public good that freely flows across different firms, industries and world regions. Thanks to this flow of ideas, the development of new technologies spreads across firms, industries and world regions from an initially very narrow set of innovators. The development of new technologies is concentrated in a few world regions, and international spillovers have a potential role to play in assuring a wider diffusion of new discoveries. Greater knowledge flows will make it easier and less costly to achieve energy efficiency gains.

This paper contributes to the literature on the costs of GHG stabilization by providing a first assessment of the potential role of international knowledge flows in fostering the development of new energy technologies. Disembodied international energy R\&D spillovers are modelled in the WITCH model. The amount of spillovers entering each world region depends on a pool of freely available knowledge and on the ability of each country to benefit from it, i.e. on its absorption capacity. Knowledge acquired from abroad combines with the domestic knowledge stock and investments, thus contributing to the production of new technologies at home.

\footnotetext{
${ }^{23}$ A similar behaviour is found for Old Europe (OLDEURO) and Canada, Japan and New Zealand (CAJANZ).
} 
We focused on the stabilization of world $\mathrm{CO}_{2}$ concentrations in the atmosphere at $450 \mathrm{ppmv}$ by the end of the 21st century (550 ppmv when considering all gases) and showed that, when international knowledge spillovers are explicitly modelled, optimal energy R\&D investments are lower than previously estimated. In particular, the strongest free-riding effects are recorded among High Income countries. The reason lies in the greater exposure of these economies to the international exchange of ideas, and thus on greater benefits in terms of potential investment savings. However, thanks to spillovers, total knowledge stocks remain unchanged and the main gain for each country is a lower expenditure in energy R\&D. These savings are not negligible in absolute terms, but are only a small share of the overall stabilization bill. The result is that stabilization costs are only slightly changed by endogenizing international energy R\&D spillovers.

Sensitivity analysis revealed that these findings are robust to a range of values attributed to the elasticity of new knowledge creation to international R\&D spillovers. High Income countries are more sensitive to variations of the parameter than Low Income countries, especially in the first decades of the century. Given the lack of empirical evidence on the actual role of international spillovers in the development of domestic technologies, it is worth concentrating the efforts in studying knowledge dynamics in High Income countries.

Our analysis has focused on innovation in terms of improved energy efficiency. Although energy efficiency is considered to be one of the most important mitigation strategies, and one that encompasses a variety of technologies, stringent stabilization will arguably require innovation to decarbonise the use of energy, and thus R\&D "backstops" might prove crucial. We leave this for future analysis, along with the investigation of additional dynamics such as spillovers to the energy sector from other sectors, or spillovers among firms, that are likely to play an important role. ${ }^{24}$

We believe this paper has achieved some relevant results in terms of policy. International spillovers are indeed an important policy channel. This is why we focused our analysis on a policy-mix in which a stabilization policy based on a global permit market is coupled with a technology policy based on transfers designed to enhance the absorption capacity in Low Income countries. The new model that we developed enabled us to assess the implications of such a policy-mix. Our results show that this policy-mix can reduce the costs of stabilizing GHG emissions. More specifically, without policies targeted to enhance absorption capacity, lump-sum income transfers do not reduce significantly the cost of ambitious stabilization targets. Low Income countries have barriers that prevent them from absorbing international knowledge spillovers. Hence, exchanges of ideas remain confined to High Income countries, where the overwhelming majority of $R \& D$ investments takes place. However, even with greater absorption capacity, the main effect is a substitution of foreign to domestic efforts, as has been found optimal for High Income countries. Therefore, greater knowledge flows and higher investments in absorption capacity in Low Income countries must necessarily be combined with specific measures aimed at reducing free-riding incentives.

It is worth noting that during the 2007 G8 Summit at Heiligendamm, in Germany, complementarytechnology-agreements for contrasting climate change and increasing energy security have been strongly advocated. The final Summit Declaration explicitly asks for "unprecedented international cooperation" in developing new technologies. ${ }^{25}$ In the spirit of the Heiligendamm Declaration, our policy exercise reinforces this message, emphasizing the key role of this type of policy intentervention.

\section{Appendix A. Supplementary data}

Supplementary data associated with this article can be found, in the online version, at doi:10.1016/j. eneco.2008.04.008.

\section{References}

Acemoglu, D., 2002. Directed technical change. Review of Economic Studies 69 (4), 781-809.

Acemoglu, D., Aghion, P., Zilibotti, F., 2006. Distance to Frontier, selection, and economic growth. Journal of the European Economic Association 4 (1), 37-74.

\footnotetext{
${ }^{24}$ We thank an anonymous referee for pointing this to us.

${ }^{25}$ Heiligendamm Summit Declaration, June 7, 2007, at Para. 43.
} 
Barrett, S., (1994), Self-enforcing International Environmental Agreements, Oxford Economic Papers, Special Issue on Environmental Economics, 46(3), 878-94.

Barrett, S., 2001. Towards a Better Climate Treaty. Policy Matters 01-29. AEI-Brookings Joint Center for Regulatory Studies, Washington, DC.

Barrett, S., 2002. Environment and Statecraft. Oxford University Press, Oxford.

Bosetti, V., Carraro, C., Galeotti, M., Massetti, E., Tavoni, M., (2006). WITCH: A World Induced Technical Change Hybrid Model, The Energy Journal, Special Issue on Hybrid Modeling of Energy-Environment Policies: Reconciling Bottom-up and Top-down, 13-38.

Bosetti, V., Massetti, E., Tavoni, M., (2007), FEEM's WITCH Model: Structure, Baseline, Solutions, FEEM Working Paper No 10/2007.

Buchner, B., Carraro, C., Cersosimo, I., Marchiori, C., 2005. Back to Kyoto? US participation and the linkage between R\&D and climate cooperation. In: Haurie, A., Viguier, L. (Eds.), Coupling Climate and Economic Dynamics. Kluwer Academic Publishers, pp. 173-204.

Buonanno, P., Carraro, C., Galeotti, M., 2003. Endogenous induced technical change and the costs of Kyoto. Resource and Energy Economics 25 (1), 11-34.

Caballero, R.J., Jaffe, A.B., 1993. How high are giants' shoulders: an empirical assessment of knowledge spillovers and creative destruction in a model of economic growth. NBER Macroeconomics Annual 1993. MIT Press, Cambridge (MA), pp. 15-74.

Carraro, C., 2001. Environmental technological innovation and diffusion. In: Folmer, H., Gabel, L., Gerking, S., Rose, A. (Eds.), Frontiers of Environmental Economics. E. Elgar, Cheltenham.

Carraro, C., Siniscalco, D., 1994. Environmental policy re-considered: the role of technological innovation. European Economic Review 38 , 545-554.

Clarke, L., Weyant, J., Edmonds, J., 2008. On the sources of technological change: what do the models assume? Energy Economics 30 , 409-424.

Coe, D., Helpman, E., 1995. International R\&D spillovers. European Economic Review 39 (5), 859-887.

Cohen, W., Levinthal, D., 1989. Innovation and learning: the two faces of R\&D. Economic Journal 99 (397), 569-596.

D'Aspremont, C., Jacquemin, A., 1988. Cooperative and noncooperative R\&D in duopoly with spillovers. The American Economic Review 78 (5), 1133-1137.

Eaton, J., Kortum, S., 1996. Trade in ideas: patenting \& productivity in the OECD. Journal of International Economics 40 (3-4), 251-278.

Eaton, J., Kortum, S., 1999. International technology diffusion: theory and measurement. International Economic Review, 1999.

Gerlagh, R., (2006), International carbon leakage. Interpreting CGE's and assessing the implications of international technology spillovers, paper presented at the 2nd Meeting of the Transust Project, Vienna, 10 October, 2006.

Gerlagh, R., Kuik, O., 2003. Trade liberalization and carbon leakage. The Energy Journal 24 (3), 97-120.

Gerschenkron, A., 1962. Economic Backwardness in Historical Perspective. Harvard University Press.

Goolsbee, A., 1998. Does government R\&D policy mainly benefit scientists and engineers? The American Economic Review 88 (2), 298-302.

Graebera, B., Spalding-Fecherb, R., Gonahc, B., 2005. Optimising trans-national power generation and transmission investments: a Southern African example. Energy Policy 33, 2337-2349.

Griffith, R., Redding, S., Van Reenen, J., 2003. R\&D and absorptive capacity: theory and empirical evidence. Scandinavian Journal of Economics 105 (1), 99-118.

Grubb, M., Carraro, C., Schellnhuber, J., (2006), Technological Change for Atmospheric Stabilization: Introductory Overview to the Innovation Modeling Comparison Project, The Energy Journal, Special Issue on Endogenous Technological Change and the Economics of Atmospheric Stabilisation, March, pp. 1-8.

Grubb, M., Hope, C., Fouquet, R., 2002. Climatic implications of the Kyoto Protocol: the contribution of international spillover. Climatic Change $54(1-2), 11-28$.

Guo, J., Yao, G., Xu, Z., Yin, Y., 2000. The investigation on Chinese nationwide interconnected grid in future. Power Engineering Society Winter Meeting, 2000. IEEE, vol. 1, pp. 6-11.

Jaffe, A.B., Trajtenberg, M., Henderson, R., 1993. Geographic localization of knowledge spillovers as evidenced by patent citations. Quarterly Journal of Economics 108 (3), 577-598.

Keller, W., (1997), Trade and the Transmission of Technology, NBER Working Paper No 6113.

Keller, W., 2004. International technology diffusion. Journal of Economic Literature 42 (3), 752-782.

Kemfert, C., 2005. Induced technological change in a multi-regional, multi-sectoral, integrated assessment model (WIAGEM). Impact assessment of climate policy strategies. Ecological Economics 54 (2-3), 293-305.

Kennedy, C., 1964. Induced bias in innovation and the theory of distribution. Economic Journal 74 (295), 541-547.

Kneller, R., 2005. Frontier technology, absorptive capacity and distance. Oxford Bulletin of Economics and Statistics 67 (1), 1-23.

Lanjouw, J.O., Mody, A., 1996. Innovation and the international diffusion of environmentally responsive technology. Research Policy 25 , 549-571.

Philibert, C., 2004. International Energy Technology Collaboration and Climate Change Mitigation. OECD Environment Directorate and International Energy Agency, Paris.

Popp, D., 2002. Induced innovation and energy prices. The American Economic Review 92 (1), 160-180.

Popp, D., 2004. ENTICE: endogenous technological change in the DICE model of global warming. Journal of Environmental Economics and Management 48 (1), 742-768.

Romer, P., 1990. Endogenous technical change. Journal of Political Economy 98, S71-S102.

Rosenberg, N., 1982. Inside the Black Box: Technology and Economics. Cambridge University Press, Cambridge.

Rosenberg, N., 1994. Exploring the Black Box: Technology, Economics, and History. Cambridge University Press, Cambridge.

Streets, D.G., 2003. Environmental benefits of electricity grid interconnections in Northeast Asia. Energy 28 (8), 789-807.

Trajtenberg, M., Henderson, R., Jaffe, A.B., (1992). Ivory tower vs corporate lab: an empirical study of basic research and appropriability, NBER Working Paper No. 4146. 